\title{
PEMILIHAN PENINGKATAN KAPASITAS PRODUKSI TERBAIK PADA CV. AIDRAT (AMSI) SUNAN DRAJAT LAMONGAN
}

\author{
Mohammad Zaki Ardiyanto, \\ Department of Management FEB UMM \\ E-mail:zaki.ard@gmail.com
}

\begin{abstract}
CV Aidrat Amsi was a business engaged in the production of Amdk that produce Products in the form of Galon, Bottle, and Glass. In CV product. Aidrat Amsi often comes with excess demand that does not match the amount of production. So the company is not able to meet the demand of its customers. The aim of this study was to analyze the best alternative to increase product capacity at $C V$ Aidrat Amasi Sunan Drajat Lamongan. The results of the study showed that CV Aidrat Amsi consisted of the best three alternatives, those are gallon machine purchasing, glass, and bottle. This study also suggested that the selection of gallon machine purchasing was the best alternative due to the having the highest EMV (Expected Monetary Value).
\end{abstract}

Keywords: capacity, overall need, decision tree

\section{PENDAHULUAN}

Pertumbuhan industri yang semakin maju dan perkembangan teknologi yang semakin pesat, menuntut perusahaan untuk meningkatkan kegiatan operasionalnya. Peningkatan pengoperasian produksi merupakan upaya yang dapat dilakukan pengusaha untuk dapat menghadapi dan memenangkan persaingan.

Setiap pelaku bisnis akan dihadapkan dengan pilihan-pilihan terkait dengan yang dilakukan. Pemilihan setiap opsi dalam komponen bisnis akan sangat berpengaruh pada bisnis, maka dari itu pengambilan keputusan sangatlah penting Dalam memproduksi suatu produk, pengusaha dituntut untuk memproduksi barang tepat waktu dalam jumlah berapapun. Ketika kapasitas produksi tidak optimal, maka akan mengganggu kelancaran proses produksi sehingga dapat menimbulkan kerugian bagi perusahaan

Kapasitas produksi ditentukan oleh sumber daya yang dimiliki seperti kapasitas mesin, kapasitas tenaga kerja, kapasitas bahan baku, dan kapasitas modal. Kapasitas sangat erat kaitannya dengan skedul produksi yang tertera dalam jadwal produksi.

Diantara faktor-faktor produksi yang paling erat dengan kapasitas produksi adalan mesin-mesin. Oleh karena itu perhitungan penambahan atau pengurangan mesin sangat diperlukan karena terbatasnya umur ekonomis suatu mesin dan efesiensi biaya yang harus dikeluarkan perusahaan. 
Decision Tree Merupakan salah satu metode/alat untuk membantu dalam pengambilan keputusan yang digunakan untuk pengambil. Didalam dicision tree terdapat halhal yang dapat mempengaruhi pengambilan keputusan nantinyaSalah satu sebab perusahaan harus tepat dalam hal perencanaan produksi ialah karena jumlah permintaan yang tidak menentu (berfluktuasi). Dengan demikian maka diperlukan suatu metode yang baku untuk mengantispasi hal tersebut.

Perencanaan kapasitas

merupakan perencanaan dan pengendalian produksi yang memeiliki peranan penting dalam perusahaan. Perencanaan kapasitas merupakan proses penentuan kapasitas yang dibutuhkan oleh perusahaan manufaktur untuk memenuhi permintaan pelanggan.

CV. Aidrat Amsi Sunan Drajat adalah perusahaan yang memproduksi air minum dalam kemasan (AMDK). Hal ini dilakukan perusahaan untuk memberi kepuasan pada pelanggan agar perusahaan tidak kehilangan pelanggan. Karena pada saat ini kapasitas produk Amdk pada CV. Aidrat (AMSI) selama tiga tahun ini mengalami kenaikan kapasitas. Tetapi perusahaan juga sudah merencanakan untuk menambah kapasitas dengan cara membeli mesin baru. Mesin yang mau ditambah yaitu mesin produksi dan pengemasan yang mampu memproduksi sesuai dengan kapasitas. maka permasalahan yang dapat didentifikasi adalah : "Alternatif peningkatan kapasitas produksi manakah yang dipilih oleh perusahaan CV. Aidrat (Amsi)?
Kapasitas produksi sangat berkaitan dengan jmlah produksi yang berada pada perusahaan pada waktu tertentu. Kapasitas produksi menentukan persyaratan modal sehingga mempengaruhi sebagian besar dari biaya.

Kapasitas merupakan suatu terobosan atau sejumlah unit yang mana tempat fasilitas dapat menyimpan, menerima atau memproduksi dalam suatu periode waktu tertentu. Jadi kapasitas adalah menyimpan, menerima dan memproduksi dalam waktu tertentu. Heizer dan Render (2015-348)

Adapun menurut Handoko (1990:297) kapasitas adalah suatu tingkat keluaran, suatu kuantitas keluaran dalam periode tertentu, dan merupakan kuantitas tertinggi yang mungkin selama periode waktu itu.

\section{TINJAUAN PUSTAKA}

Kapasitas produksi sangat berkaitan dengan jmlah produksi yang berada pada perusahaan pada waktu tertentu. Kapasitas produksi menentukan persyaratan modal sehingga mempengaruhi sebagian besar dari biaya. Ada beberapa pendapat mengenai pengertian Kapasitas, yaitu menurut Heizer dan Render (2015-348)

Kapasitas merupakan suatu terobosan atau sejumlah unit yang mana tempat fasilitas dapat menyimpan, menerima atau memproduksi dalam suatu periode waktu tertentu. Kapasitas desain merupakan output yang maksimum secara teori pada suatu sistem dalam suatu periode waktu tertentu pada kondisi idealnya. Kapasitas efektif adalah kapasitas yang diperkirakan dapat dicapai oleh sebuah perusahaan 
dengan keterbatasan operasi yang ada sekarang. Kapasitas Efesien (efficiency) Persentase desain kapasitas yang benar-benar tercapai. Bergantung pada bagaimana tempat fasilitas dipergunakan dan dikelola.

kapasitas efesien mengukur seberapa baik fasilitas atau mesin ketika digunakan. Keputusan mengenai kapasitas berkaitan erat dengan keptusan fungsional lainnya, maka perencanaan yang tepat sangat dibutuhkan dan salah satu caranya dengan menerapkan koordinasi lintas fungsional yang menerapkan strategi kapasitas yang tepat. Dan keputusan kapasitas tidak hanya diambil berdasarkan keputusan kapasitas saja, namun berkaitan dengan kebutuhan dan kepentingan keptusan fungsional lainnya agar semua keputusan fumgsional diperusahaan dapat berjalan dengan baik.

Menurut Heizer \& Render (2015-779) Pohon keputusan (Decision Tree) merupakan sebuah tampilan grafis proses pengambilan keputusan yang mengindikasikan alternatif keputusan yang ada, kondisi alamiah dan peluangnya, dan juga imbalan bagi setiap kombinasi alternatif keputusan dan kondisi alamiah.

\section{METODE PENELITIAN}

Penelitian ini dilakukan di CV. Aidrat Amsi di Desa Paciran yang bertepatan di Pondok Pesantren Sunan Drajad kecamatan Paciran, Kabupaten Lamongan. Jenis penelitian ini adalah dengan menggunakan aplikasi model, yaitu penelitian yang menekankan pada pemecahan masalah-masalah praktis terhadap beberapa alternatif tindakan dalam proses pembuatan keputusan bisnis (Indrianto dan Supomo, 2009:24).

Definisi operasional variabel adalah pengertian variable(yang diungkap dalam definisi konsep) tersebut, secara operasional, secara praktek, secara riil, secara nyata dalam lingkup penelitian atau objek yang diteliti (Prasetya, 2010)..

Alternatif Untuk meningkatkan pendapatan terdapat beberapa alternatif yang dapat dilakukan perusanhaan. Paket AMDK mesin Kemasan Galon dan Gelas, Paket AMDK Kemasan Botol Dan Gelas, Paket AMDK Kemasan Peristiwa mencerminkan suatu permintaan yang mungkin akan terjadi pada setiap alternatif keputusan. Permintaan dibagi dalam berbagai peristiwa yaitu, permintaan tinggi, sedang, dan rendah.

Payoff merupakan laba (benefits) atau biaya yang dihasilkan/diakibatkan dari atau oleh kombinasi suatu keputusan dan suatu keadaan dasar yang diacak. EMV (Expected Monetary Value) atau perkiraan nilai dalam bentuk uang adalah suatu kriteria yang memanfaatkan probabilitas tentang terjadinya situasi (keadaan) masa depan dalam pemilihan alternatifalternatif keputusan (Kasim, 1989). 


\begin{tabular}{|c|c|c|}
\hline \multicolumn{3}{|c|}{$\begin{array}{l}\text { HASIL PENELITIAN DAN } \\
\text { PEMBAHASAN } \\
\text { Tabel 1. Tabel Peristiwa permintaan }\end{array}$} \\
\hline No & Skala & Kelas \\
\hline 1 & $\begin{array}{c}666.810 .560- \\
733.509 .666\end{array}$ & Rendah \\
\hline 2 & $\begin{array}{c}733.509 .667- \\
800.208 .772\end{array}$ & Sedang \\
\hline 3 & $\begin{array}{c}800.208 .773- \\
866.907 .880\end{array}$ & Tinggi \\
\hline
\end{tabular}

Berdasarkan data diatas, maka dapat diketahui jumlah permintaan Amdk rendah yaitu 13 kali, permintaan sedang yaitu $11 \mathrm{kali}$, dan permintaan tinggi yaitu 12 kali. maka tahap selanjutnya adalah menghitung probabilitas. Probabilitas dapat diketahui dengan permintaan rendah dibagi dengan jumlah bulan.

Tabel 2. Pendapatan (ml) Dikategorikan sesuai Rentang Skala.

\begin{tabular}{lrlll}
\hline No & & Rendah & Sedang & Tinggi \\
\hline & 1 & 669.547 .760 & 764.596 .360 & 827.330 .640 \\
& 2 & 709.325 .800 & 792.091 .800 & 812.326 .200 \\
& 3 & 670.508 .520 & 759.549 .120 & 863.564 .320 \\
& 4 & 694.639 .840 & 744.736 .480 & 820.520 .320 \\
& 5 & 708.279 .640 & 791.067 .080 & 834.374 .480 \\
& 6 & 672.776 .240 & 777.745 .200 & 815.623 .360 \\
& 7 & 687.763 .800 & 768.853 .360 & 838.392 .800 \\
& 8 & 666.810 .560 & 789.127 .440 & 832.502 .080 \\
& 9 & 698.699 .160 & 757.330 .520 & 825.816 .760 \\
& 10 & 711.711 .960 & 787.508 .640 & 866.907 .880 \\
& 11 & 716.202 .720 & 789.769 .000 & 849.247 .160 \\
& 12 & 725.182 .640 & & 817.635 .840 \\
& 13 & 731.152 .480 & & \\
\hline Jumlah & 13 & 11 & 12 \\
\hline pro & 0.36 & 0.30 & 0.33 \\
\hline \multicolumn{4}{c}{}
\end{tabular}

Berikut ini merupakan perhitungan probabilitas masing masing permintaan. Untuk permintaan tinggi, berdasarkan dari tabel rentang skala, diketauhi batas rentang skala pendapatan tinggi adalah 800,208,773 - 866,907,880, maka diketauhi jumlah permintaan tinggi pada tahun 2014 sampai tahun 2016 adalah sebanyak 12 kali, sehingga probabilitas permintaan tinggi $=\frac{12}{36}=0,33$.

Untuk permintaan sedang, berdasarkan dari tabel rentang skala, diketauhi batas rentang skala permintaan sedang adalah 733.509.667 - 800.208.772, maka diketauhi jumlah permintaan sedang pada tahun 2014 sampai desember 2016 adalah sebanyak 11 kali, sehingga probabilitas permintaan permintaan sedang $=\frac{11}{36}=0.30$

Untuk permintaan rendah, berdasarkan dari tabel rentang skala, diketauhi batas rentang skala pendapatan rendah adalah 666,810,560 - 733,509,666, maka diketauhi jumlah permintaan rendah pada tahun 2014 sampai desember 2016 adalah sebanyak 13 kali. sehingga probabilitas permintaan permintaan rendah $=\frac{13}{36}=0,36$

Berdasarkan tabel diatas dapat disimpulkan bahwa peristiwa pendapatan rendah memiliki probabilitas sebesar 0.36 , peristiwa 
pendapatan sedang 0.30 , dan untuk peristiwa pendapatan tinggi 0.33 .

Payoff Alternatif merupakan beberapa skema alternatif dalam pengambilan keputusan dalam pemilihan mesin usaha Amdk yang terdiri dari 3 alternatif seperti yang ada ditabel bawah.

Tabel 3. Pay Off Pembelian Mesin Galon, Gelas, dan Botol

\begin{tabular}{lrrr}
\hline Keterangan & Rendah $(\mathrm{Rp})$ & Sedang $(\mathrm{Rp})$ & \multicolumn{1}{r}{ Tinggi $(\mathrm{Rp})$} \\
\hline $\begin{array}{l}\text { Pendapatan } \\
\text { galon, cup, botol }\end{array}$ & $1,084,140,000$ & $1,255,294,000$ & $1,348,634,000$ \\
Pengeluaran & & & \\
Biaya tetap & & & \\
Gaji Pegawai & 14.400 .000 & 14.400 .000 & 14.400 .000 \\
Bbm genset & 768,000 & 768,0000 & 768,000 \\
Biaya variabel & & & \\
tenaga Kerja & $12,540,530$ & $16,759,970$ & $18,062,784$ \\
pemeliharaan. & $4,267,431$ & $5,703,270$ & $6,146,605$ \\
Mesin & & & \\
Biaya genset & $1,152,000$ & $1,152,000$ & $1,152,000$ \\
Biaya listrik & $7,007,985$ & $9,365,922$ & $10,093,969$ \\
Biaya penonlong & $637,525,000$ & $728,626,000$ & $775,502,000$ \\
jumlah Biaya & $677,660,946$ & $776,775,162$ & $826,125,358$ \\
pay off & $406,479,054$ & $478,518,838$ & $522,508,642$ \\
\hline
\end{tabular}

Tabel 4. Pay Off Pembelian Mesin Gelas, dan Botol

\begin{tabular}{|c|c|c|c|}
\hline Keterangan & Rendah (Rp) & Sedang (Rp) & Tinggi (Rp) \\
\hline $\begin{array}{c}\text { Pendapatan } \\
\text { cup, botol }\end{array}$ & $81,9807,000$ & $927,840,000$ & $962,088,000$ \\
\hline $\begin{array}{c}\text { Pengeluaran } \\
\text { Biaya tetap }\end{array}$ & & & \\
\hline Gaji Pegawai & $14,400,000$ & $14,400,000$ & $14,400,000$ \\
\hline $\begin{array}{c}\text { Biaya genet } \\
\text { Biaya }\end{array}$ & 768,000 & 768,000 & 768,000 \\
\hline Variabel & & & \\
\hline Tenaga Kerja & $17,579,040$ & $21,105,563$ & $25,663,979$ \\
\hline $\begin{array}{c}\text { Pemeliharaan } \\
\text { Mesin }\end{array}$ & $5,981,992$ & $7,182,036$ & $8,732,884$ \\
\hline Bbm genset & $1,152,000$ & $1,152,000$ & $1,152,000$ \\
\hline Biaya listrik & $7,428,459$ & $9,039,484$ & $9,866,506$ \\
\hline $\begin{array}{c}\text { Biaya } \\
\text { Penolong }\end{array}$ & $528,682,000$ & $593,792,000$ & $616,336,000$ \\
\hline jumlah Biaya & $579,344,767$ & $651,850,226$ & $682,697,623$ \\
\hline pay off & $243,815,509$ & $280,400,917$ & $285,168,631$ \\
\hline
\end{tabular}


Tabel. 5 Pay Off Pembelian Mesin Galon, Gelas.

\begin{tabular}{lrrr}
\hline Keterangan & Rendah(Rp) & Sedang(Rp) & \multicolumn{1}{c}{ Tinggi (Rp) } \\
\hline $\begin{array}{l}\text { Pendapatan } \\
\quad \text { galon, }\end{array}$ & $951,757,000$ & $109,6390,000$ & $1,192,512,000$ \\
$\begin{array}{l}\text { gelas } \\
\text { Pengeluaran } \\
\quad \text { Biaya tetap }\end{array}$ & & & \\
$\begin{array}{l}\text { Gaji Pegawai } \\
\text { Bbm genset }\end{array}$ & $14,400,000$ & $14,400,000$ & $14,400,000$ \\
$\begin{array}{l}\text { Biaya } \\
\text { variabel }\end{array}$ & & & \\
Tenaga Kerja & $12,450,532$ & $16,967,673$ & $17,970,641$ \\
pemeliharaan. & $4,236,806$ & $5,773,949$ & $6,115,250$ \\
$\begin{array}{l}\text { Mesin } \\
\text { Bbm genset }\end{array}$ & $3,734,849$ & $5,089,879$ & $5,390,744$ \\
$\begin{array}{l}\text { Biaya listrik } \\
\text { Biaya }\end{array}$ & $6,957,692$ & $9,481,993$ & $10,042,478$ \\
penonlong & $557,163,000$ & $636,314,000$ & $684,796,000$ \\
jumlah Biaya & $598,942,879$ & $688,072,494$ & 738715,113 \\
pay off & $352,814,121$ & $408,362,506$ & $453,796,887$ \\
\hline
\end{tabular}

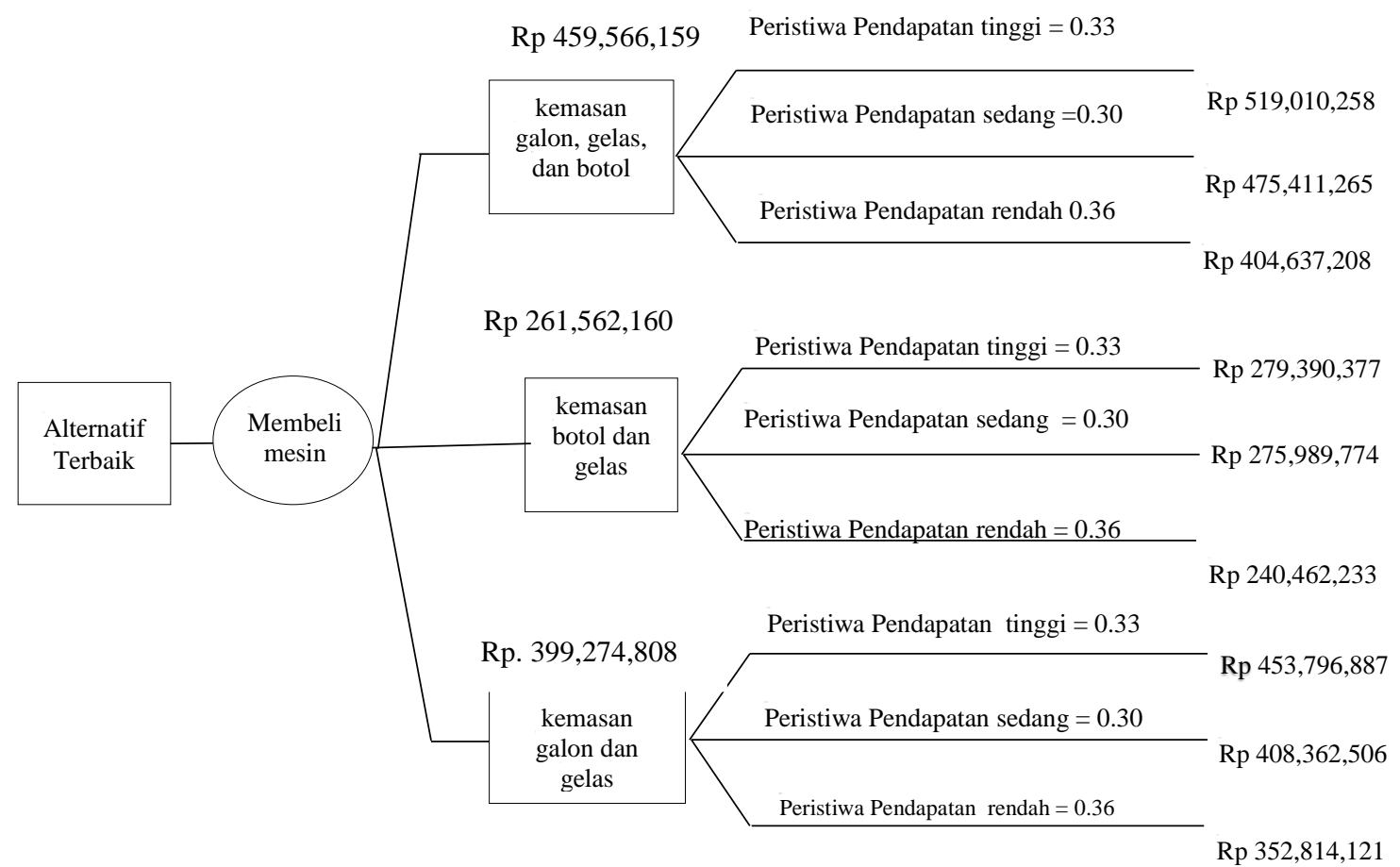

Gambar 1. Pohon Keputusan 
Tabel 7. Tabel Perhitungan EMV (Expected Monetary Value)

\begin{tabular}{|c|c|c|c|}
\hline No. & EMV & $\begin{array}{l}\mathrm{EMV}=\sum \text { (Probabilitas } \mathrm{x} \\
\text { Payoff yang diharapkan) }\end{array}$ & Hasil EMV \\
\hline 1 & $\begin{array}{c}\text { Galon, Gelas, dan } \\
\text { Botol }\end{array}$ & $\begin{array}{c}\{(0.36)(\text { Rp. 406,479,054) }\}+ \\
\{(0.30)(\text { Rp. } 478,518838)\}+ \\
\{(0.33)(\text { Rp. } 522,508,642)\}\end{array}$ & Rp. 462,315,963 \\
\hline 2 & $\begin{array}{l}\text { Kemasan Gelas, } \\
\text { dan Botol }\end{array}$ & $\begin{array}{c}\{(0.36)(\text { Rp. } 243,815,509)\}+ \\
\{(0.30)(\text { Rp. 280,400,917) }\}+ \\
\{(0.33)(\text { Rp. } 285,168,631)\}\end{array}$ & Rp. $265,999,507$ \\
\hline 3 & $\begin{array}{l}\text { Kemasan Galon, } \\
\text { dan Gelas }\end{array}$ & 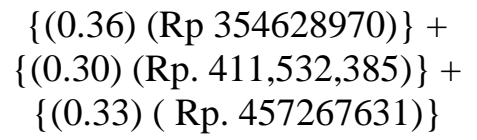 & Rp. $402,024,463$ \\
\hline
\end{tabular}

Peningkatan kapasitas produksi adalah upaya yang dilakukan oleh perusahaan untuk dapat memenuhi kebutuhan para pelanggan upaya pengendalian produksi di perusahaan. Dalam penelitian ini, untuk meningkatkan kapasitas produksi perusahaan dilakukan dengan pemilihan terhadap tiga alternatif peningkatan kapasitas produksi perusahaan,yaitu dengan pembelian Mesin Galon, Gelas, dan Botol

Alternatif pembelian mesin merupakan alternatif yang akan memberikan peningkatan kapasitas yang paling tinggi. Ketika perusahaan akan melakukan pembelian mesin maka perusahaan perlu mempertimbangkan umur ekonomis mesin produksii serta beban penyusutannya.

Berdasarkan analisis pemilihan alternatif peningkatan kapasitas produksi Amdk CV. Aidrat Amsi dengan memberikan pilihan terhadap tiga alternatif peningkatan kapasitas produksi

Setelah menghitung kebutuhan rata-rata, tahap selanjutnya adalah membuat pohon keputusan. Sebelum membuat pohon keputusan adalah menghitung rentang skala, probabilitas. Rentang skala pada CV. Aidrat Amsi untuk permintaan rendah, permintaan sedang, dan permintaan tinggi

Pohon keputusan merupakan model skematik dari alternatifalternatif yang tersedia untuk pengambilan keputusan yang disertai dengan akibat akibat yang mungkin ditimbulkannnya (Krajewski dan Ritzman, 199:76). untuk menentukan alternatif terbaik seorang pembuat keputusan harus menganalisa, menghitung perkiraan nilai moneter dari masing-masing alternatif dan kemudian memilih alternatif yang menghasilkan perkiraan nilai moneter yang paling tinggi.

\section{SIMPULAN}

Berdasarkan hasil analisis data mengenai pemilihan alternative peningkatan kapasitas produksi Amdk CV. Aidrat Amsi dengan pemilihan terhadap tiga alternatif peningkatan kapasitas produksi $\mathrm{CV}$. Aidrat Amsi, yaitu mesin galon, gelas, botol dengan nilai EMV adalah Rp 459,566,159, mesin gelas, botol dengan nilai EMV Rp $261,562,160$, mesin galon dan gelas 
dengan nilai EMV Rp 399,274,808

Berdasarkan dari tiga alternatif terbaik yang dapat dilakukan oleh CV. Aidrat Amsi adalah dengan pembelian mesin produksi/mesin Amdk pembelian mesin galon, gelas, botol. Karena memiliki nilai EMV tertinggi, yaitu Rp. 459,566,159.

Perusahaan dapat melakukan pembelian paket mesin Amdk Untuk dapat meningkatkan kapasitas produksinya, karena dengan pembelian mesin Amdk perusahaan akan mengalami peningkatan terhadap jumlah yang akan di produksi Bagi pihak lain dalam hal ini adalah menyempurnakannya dengan menggunakan metode yang berbeda untuk peningkatan kapasitas produksi di suatu perusahaan sehingga penelitian ini dapat lebih berkembang.

\section{DAFTAR PUSTAKA}

Anwar, Sanusi. 2011. Metodologi Penelitian Bisnis. Jakarta: Salemba Empat

Hakim, Ahmad Lukman, 2015, Pemilihan Alternatif Terbai untuk Meningkatkan Kapasitas Produksi Pada Produk Rantang di Home Industry Gadjah Delta Sidoarjo

Assauri, sofjan, 1993, Manajemen produksi dan operasi, Edisi ke4, Lembaga Penerbit Fakultas Ekonomi Universitas Indonesia, Jakarta.

Handoko, T. Hani, 2000, Dasar- dasar Manajemen Produksi dan Operasi, Edisi 1, BPFE, Yogyakarta

Heizer, Jay dan Barry Render, 2015.Manajemen Operasi (Buku Edisi 11), Salemba Empat, Jakarta.

Indriantoro, Nur., Bambang Supomo, 2009. Metodologi Penelitian Bisnis untuk Akuntansi dan Manajemen, Edisi Pertama. Yogyakarta : BPFE Yogyakarta.

Izzatabillah, Dina, 2008, Pemilihan Alternatif Peningkatan Kapasitas Produksi Pada Penggilingan Padi UD. Tani Makmur

Krajeski, Lee J., Barry P. Ritzman, 1999, Operation Manajemen Processes and Value Chains, Prentice Hall, Inc. Upper Saddle River, USA

Saepudin, aep, 2008, alternative meningkatkan kapasitas produksi dengan menentukan jumlah mesin jahit yang paling menguntungkan secara kuantitatif pada perusahaan Tjakra Tailor

Sekaran, Uma, 2006. Metodologi Penelitian Untuk Bisnis, Jakarta: Salemba Empat.

Syamsul Ma'arif dan Hendri Tanjung, 2003, Manajemen Operasi, Edisi Pertama, PT. Grasindo, Jakarta.

Yamit, Zulian, 2003, Manajemen Produksi dan Operasi, Edisi 2, Ekonisia, Yogyakarta. 